\title{
AGREGAÇÃO DE VALOR À AGRICULTURA FAMILIAR: UMA ALTERNATIVA PARA O DESENVOLVIMENTO TERRITORIAL SUSTENTÁVEL
}

\author{
AGGREGATION OF VALUE TO THE FAMILY FARMING: UN \\ ALTERNATIVE TO THE SUSTAINABLE TERRITORIAL \\ DEVELOPMENT
}

\author{
Elvira Maria Radwanski \\ Agente Administrativo na Prefeitura Municipal de Guaramirim - SC - Brasil \\ Carlos Alberto Cioce Sampaio \\ Pontifícia Universidade Católica do Paraná - PR - Brasil \\ Maria do Carmo Martins Sobral \\ Universidade Federal de Pernambuco - PE - Brasil
}

\begin{abstract}
Resumo: $O$ presente artigo apresenta resultados de um projeto realizado no município de Guaramirim, Estado de Santa Catarina, e voltado à agregação de valor e sustentabilidade do meio rural, implementado em pequenas propriedades rurais, onde predomina a agricultura familiar. Temse como objetivo verificar se o projeto "Valorizar o Artesanal", implantado como estratégia para o desenvolvimento territorial sustentável do meio rural do município de Guaramirim (SC), obteve os resultados esperados e quais foram os impactos observados sobre a população atendida pelo projeto a partir da instalação do mesmo. Como metodologia para a realização da pesquisa supracitada predominou o estudo de caso. Como procedimento, utilizou-se entrevistas por meio de questionários e observação de campo. Descreve-se e analisa-se a experiência entre 2001 e 2008 . O Projeto vem possibilitando o aumento da renda às famílias agricultoras, garantindo sua segurança alimentar e a dos consumidores, a partir da legalização do comércio de produtos artesanais comestíveis de origem animal e vegetal, elaborados nas propriedades rurais do município de Guaramirim. Como consequência, os atores sociais tem se sentindo valorizados e se identificam com o território, promovendo, assim, a sustentabilidade de seus modos de vida e de produção.
\end{abstract}

Palavras-chave: Agregação de valor. Agricultura familiar. Desenvolvimento territorial sustentável.

Abstract: The paper leads of resulted the projects of sustainable and aggregation of value in the agricultural in small rural properties, where familiar agriculture predominates, in the city of Guaramirim, State of Santa Catarina, Brazil. The article has as objective to verify whether the project "Enhancing the Craft", developed as a strategy for sustainable territorial development of rural areas of the municipality of Guaramirim (SC), achieved the expected results and what were the impacts observed on the population served by the project. As methodology was used a qualitative study, intervening research, from interviews until participate observation. The project enable the increase of the income the rural families, guaranteeing its alimentary security and of the consumers, the legalization of the handicraft product, animal or vegetal origin, to sale on the market. The social actors have pride their identity and territory.

keywords: Aggregation of value; Familiar agriculture; Sustainable territorial development

\section{Introdução}

Ao longo dos anos o ambiente rural tem se modificado. No passado, o meio rural era reservado para atividades agrícolas e moradia dos agricultores. 
Atualmente, encontram-se outras atividades e outras formas de ocupação nesse espaço.

Segundo Silva (1998, p. 117), esse "Novo Rural" compõe-se basicamente de três grandes grupos de atividades:

\footnotetext{
1 - agropecuária moderna, baseada em commodities e intimamente ligada às agroindústrias;

2 - conjunto de atividades não agrícolas, ligadas à moradia, ao lazer e a várias atividades industriais e de prestação de serviços;

3 - conjunto de "novas" atividades agropecuárias, localizadas em nichos especiais de mercados.
}

Outro ponto a ser considerado é o avanço de forma desordenada do perímetro urbano sobre o rural. Quando não há plano diretor definindo limites de zoneamento no município, pode ocasionar interesse e especulação imobiliária para instalação de condomínios na zona rural. O que sugere preocupação principalmente para pequenos agricultores familiares, tal como acontece no município de Guaramirim, em Santa Catarina, pois, estes muitas vezes não possuem condições de saldar taxas territoriais, quando estas são referenciadas como urbanas. Pois, na maioria das vezes, são mais altas do que o imposto territorial rural, o que pode ocasionar a venda de suas propriedades por não possuírem rendimentos oriundos do trabalho para saldá-las. O que acaba ocorrendo é que os até então agricultores se transferem para outras regiões do interior ou senão para núcleos urbanos, e em ambas as opções perdem vínculos de identidade territorial. Quando ainda migram para cidades, à busca de meios de subsistência, geralmente no setor industrial e serviços, ficam em desvantagem quando competem com mão de obra residente mais qualificada. Abramovay (2000) sugere que os filhos de agricultores são os que mais encontram dificuldades para se integrarem nos mercados urbanos de trabalho.

A partir deste cenário, os pequenos proprietários rurais vêm utilizando de criatividade para otimizar todos os espaços da propriedade, bem como as possibilidades de serviços ambientais, principalmente por serem gratuitos, além de pensar em um contexto de desenvolvimento territorial sustentável. Diversificar as culturas e agregar maior valor à sua produção, no sentido de potencializar o empreendimento rural, oportuniza às unidades familiares integrarem-se ao mercado, competitivo e exigente, levando-os a se associarem em contexto de redes de cooperação socioeconômica ou sociopolítica, como os arranjos produtivos locais (GUZATTI, TURNES \& SAMPAIO, 2014).

No município de Guaramirim, as propriedades rurais muitas vezes se utilizam da prática da monocultura, ou seja, explora-se o solo com exclusividade para uma só cultura agrícola, principalmente o arroz irrigado. A monocultura como única geradora de renda e trabalho coloca muitas vezes em risco a sustentabilidade da agricultura familiar, quando há baixo preço no mercado ou perda de safra provocada por más condições climáticas ou de logística da própria colheita. Faz-se necessário potencializar os espaços, diversificar as culturas e agregar valor ao que é produzido nas propriedades rurais, como garantia de novas fontes de trabalho e renda, garantindo-se assim a permanência do agricultor no campo (PMG, 2013). 
Diante desse contexto, o artigo tem como objetivo verificar se o projeto "Valorizar o Artesanal", implantado como estratégia para o desenvolvimento territorial sustentável do meio rural do município de Guaramirim (SC), entre 1997 e 2008, obteve os resultados esperados e quais foram os impactos observados sobre a população atendida pelo projeto a partir da implementação do mesmo.

A seleção do projeto "Valorizar o Artesanal", como objeto de estudo, deveu-se ao seu reconhecimento Estadual e Nacional que viria em 2010, a partir do Fórum Regional Sul de Vigilância Sanitária da ANVISA, em Florianópolis, como o melhor trabalho de Santa Catarina e apresentado no Simpósio Brasileiro da Vigilância Sanitária (SIMBRAVISA) em Belém, como estratégia fundamental de geração de renda, segurança alimentar e preservação do meio ambiente.

Em 2010, também viria a ser desenvolvido, com recursos do Governo do Estado de Santa Catarina, um plano para o desenvolvimento da atividade do turismo rural no município de Guaramirim/SC, priorizando o processo de agregação de valor à agricultura familiar, proporcionado pelo Projeto intitulado como "O verdadeiro sabor de Guaramirim", confeccionando novo material de divulgação, cartilha, folder e banners, e novo rótulo. Para tanto, foi utilizada a Estação Ferroviária ${ }^{1}$ como referência do município para divulgar o projeto e as propriedades integradas.

Neste mesmo ano, foi implantada uma feira semanal para comercialização dos produtos agrícolas, nas sextas-feiras e sábados, em espaço junto à Estação Ferroviária, no centro da cidade. A realização de feira anual de produtos agrícolas intitulada "Feira das Delícias da Agricultura Familiar", que possibilita a divulgação e a comercialização de produtos do meio rural de vários municípios do Estado de Santa Catarina.

Em 2011, seria implantada a escola ERFAG - Escola Rural para Família de Agricultores de Guaramirim, para crianças a partir de 9 anos de idade, no período do contraturno escolar, como um projeto de estímulo ao empreendedorismo, pensando no perfil de filhos de agricultores, com o objetivo de estimular permanência desses no meio rural.

Constituir-se-ia, ainda neste ano, a Cooperativa de Produção Agrícola Familiar do Vale do Itapocu - Cooper Itapocu -, que objetiva legalizar e comercializar os produtos de forma organizada, oportunizando aos produtores rurais a comercialização para além das fronteiras do município e em maior escala.

Em 2012, haveria aumento do número de participantes, com a integração de mais duas propriedades devidamente legalizadas. Há outras que estão em processo de adequação para se inserirem ao projeto.

\footnotetext{
${ }^{1}$ Localiza-se no centro do município e é a edificação mais antiga da cidade. Para Guaramirim a Estação Ferroviária representa parte da história da colonização do município. Ela foi construída em 1910 e em 1990 foi transformada em estação Rodoferroviária. É o patrimônio mais antigo do município (PMG, 2013).
} 


\section{Metodologia}

Como metodologia para a realização desta pesquisa, predominou a abordagem qualitativa por meio do estudo de caso. Como procedimento, utilizouse entrevistas por meio de questionários e observação de campo. O período temporal que delimita o estudo é de onze anos, entre 1997 e 2008.

Cabe ressaltar que a primeira autora do artigo é técnica da prefeitura de Guaratuba, onde exerceu, na época, funções de assessoria ao projeto "Valorizar o Artesanal", implantado no município de Guaramirim (SC). De sua aproximação com o estudo, resultou uma dissertação referenciada na bibliografia em nome de Radwanski (2008).

Como procedimento foi utilizado roteiro de coleta de dados, entre os quais a realização de entrevistas com três grupos de atores sociais, totalizando 18 pessoas, conforme demonstra o Quadro I.

\begin{tabular}{|c|c|c|}
\hline Grupos de atores & Denominações & $\begin{array}{l}\text { Número de } \\
\text { Entrevistas }\end{array}$ \\
\hline Poder Público & $\begin{array}{l}\text { (1) Secretarias Municipais de Desenvolvimento } \\
\text { Econômico, (2) de Saúde, e (3) de Agricultura e } \\
\text { Meio Ambiente; (4) EPAGRI e (5) Sindicato dos } \\
\text { Trabalhadores Rurais, }\end{array}$ & 5 \\
\hline Agricultores & $\begin{array}{l}\text { (6) Agricultores integrantes do projeto e (7) } \\
\text { Agricultores com potencial para adequação do } \\
\text { Projeto. }\end{array}$ & 8 \\
\hline Outras instituições & $\begin{array}{l}\text { (8) Núcleo de Turismo da Estrada Jacu-Açu, (9) } \\
\text { Conselho Municipal de Desenvolvimento } \\
\text { Econômico (CODEC), (10) Câmara Técnica da } \\
\text { Agricultura, (11) Associação dos Bananicultores de } \\
\text { Guaramirim, (12) Associações de Moradores e } \\
\text { (13) Companhia de Desenvolvimento } \\
\text { Agropecuário de Santa Catarina (CIDASC). }\end{array}$ & 5 \\
\hline
\end{tabular}

Quadro 1. Grupos de Atores Sociais

Fonte: Radwanski (2008).

Para a análise de dados foram utilizadas categorias operativas que representam as palavras-chave, as quais serviram como referência para o roteiro de coleta de dados, como segue sistematizada em 3 agrupamentos:

No primeiro grupo, utilizaram-se as categorias a seguir: (1) Transformação do produto in natura de forma artesanal; (2) Oferta de novos produtos para os consumidores; (3) Crescimento da demanda de fornecedores; (4) Melhoria na assistência técnica; (5) Melhoria na comercialização; (6) Investimentos financeiros; (7) Obtenção de novos conhecimentos; (8) Certificação dos produtos; (9) Incentivo à exploração de novas atividades. 
Quanto ao segundo grupo, empregaram-se as categorias: (1) Satisfação em ser agricultor; (2) Valorização do conhecimento tradicional; (3) Melhoria da qualidade de vida, e (4) Senso de identidade territorial.

O terceiro grupo faz referência às seguintes categorias: Oportunidades de trabalho e renda; (2) Uso sustentável dos recursos naturais; (3) Racionalização do uso de agrotóxicos; (4) Valorização do valor estético da natureza; e (4) Ação coletiva e gestão participativa.

\section{Desenvolvimento Territorial e Regional}

Nesta seção, pretende-se abordar, de forma sucinta, os temas desenvolvimento territorial e desenvolvimento regional, abrangendo as dimensões social, cultural, ambiental e físico-territorial, político-institucional, científicotecnológica e econômica.

À guisa de introdução do tema, faz-se necessário elucidar o que se entende por desenvolvimento. Bassan e Siedenberg (2003, p. 145) assim o definem:

O desenvolvimento passa a ser tratado a partir de critérios, como a eficiência produtiva, a satisfação das necessidades humanas e o atendimento dos objetivos da sociedade, o que implica uma boa administração dos escassos recursos.

Nesta mesma linha de raciocínio, Franco (2000, p. 24) elege elementos básicos que propiciam o desenvolvimento:

\footnotetext{
Gerar renda, multiplicar o número de proprietários produtivos, elevar o nível de escolaridade da população e aumentar o número de organizações da sociedade civil. Ou seja, aumentar a produção e democratizar o acesso à riqueza, ao conhecimento e ao poder (no sentido de empoderar as populações).
}

Com base no pressuposto de que crescimento econômico não implica, necessariamente, desenvolvimento, Bassan e Siedenberg (2003, p. 138) distinguem os países chamados desenvolvidos dos subdesenvolvidos, quando afirmam que os primeiros "procuram aliar a seu crescimento econômico (aumento da renda e da produtividade) o desenvolvimento econômico e social, destinado a atender as necessidades sociais da sua população". Continuam os autores: "[...] ainda estão no estágio em que o crescimento parece ser essencial, preocupados, meramente, com aumento da renda, ou pensando em crescimento como sinônimo de desenvolvimento". Deste ponto de vista, crescimento estaria atrelado à ideia de que se produz aumenta-se a renda.

Para Hoff e Stiglitz (2001, p. 389), desenvolvimento "não é mais visto primariamente como um processo de acúmulo de capital, mas antes como um processo de mudança organizacional". Esse deve promover a elevação de capital 
social, incentivando a participação de todos os atores na elaboração e execução de um projeto democrático, visando à sustentabilidade.

Ressalta-se a importância do Estado nesse processo, visto por Brandão (2004) como órgão promotor de projetos que visam ao desenvolvimento territorial e que requerem elevação do capital social, democratizem o acesso aos bens públicos, solicitem estudos de impacto ambiental, implantando ações para a conservação do meio ambiente e que se articulem de forma a promover o desenvolvimento e mobilizar os recursos endógenos de uma região.

Faz-se necessário destacar elementos que constituem o processo de desenvolvimento territorial e local, tais como: as forças endógenas - capital social, econômico, ambiental, etc. - e o desempenho do tecido sociocultural. Nessa linha de visão, Brandão (2005, p. 9) destaca:

\begin{abstract}
A questão territorial ganha evidência, ao mesmo tempo em que ocorre certa banalização e vulgarização da problemática do desenvolvimento de cidades, regiões e países. Não obstante a natureza estrutural, histórica e dinâmica destas 'questões espaciais', elas foram deslocadas, muitas vezes, para o lugar-comum do voluntarismo, cristalizando um grande consenso, que por vezes exagera no endogenismo e na capacidade de autopropulsão das regiões e localidades.
\end{abstract}

O desenvolvimento passou a depender do desempenho do território, de capacitação institucional, elementos culturais, nível de relacionamento e levantamento dos potenciais para negócios mais promissores, onde os atores se congregam e se aproximam de forma cooperativa. $O$ espaço torna-se território, 0 qual se torna componente permanente de desenvolvimento, onde os atores se encontram e organizam formas de regulação social. O território passa a ser entendido como um novo ponto para interferência do Estado, e o desenvolvimento territorial torna-se uma forma de valorizar os atributos político e cultural de uma comunidade e dos atores sociais ali existentes.

Aqui cumpre destacar que se considera território como área restrita, circunscrita a determinado grupo de atores com potencialidades e objetivos convergentes, diferente de região, compreendida como área simplificada, para cujo centro convergem determinados interesses comuns.

Nesse direcionamento, Abramoway (2000, p. 385) define território como:

\footnotetext{
Um território representa uma trama de relações com raízes históricas, configurações políticas e identidades [...]. São o resultado de formas específicas de interação social, da capacidade dos indivíduos, das empresas e das organizações locais em promover ligações dinâmicas, capazes de valorizar seus conhecimentos, suas tradições e a confiança que foram capazes, historicamente, de construir.
} 
Para Vasquez-Barquero (1998, p. 78) desenvolvimento territorial é definido como:

\begin{abstract}
Um processo de crescimento econômico e de mudanças estruturais que conduz a uma melhoria em nível de vida da população local, em que se podem identificar três dimensões: econômica, em que os empresários locais usam sua capacidade para organizar os fatores produtivos locais com nível de produtividade suficiente para serem competitivos no mercado; outra sociocultural, em que os valores e as instituições servem de base no processo de desenvolvimento; e finalmente uma dimensão político-administrativa em que as políticas territoriais permitem criar um entorno econômico local favorável, protegê-lo de interferências externas e impulsionar o desenvolvimento local.
\end{abstract}

Pontes (1986 e 1987, p. 325) sugere que a região é vista como "uma dimensão espacial das especificidades sociais em uma totalidade espaço-social". Bassan e Siedenberg (2003, p. 141), ante a diversidade de definições de região, fazem um apanhado geral dessas várias definições, propondo:

[...] considera-se como região uma porção do espaço com características naturais específicas que, ao longo do seu processo de formação histórico-cultural, foi configurando uma identificação social, econômica e política, a fim de atender às necessidades de sua população, delimitando uma identidade regional própria.

Dessa forma, cada região tem seu estilo próprio de desenvolvimento. Considerando o desafio do combate à pobreza, a melhoria das condições de vida da população, o crescimento econômico das periferias, o desenvolvimento humano e social, a conquista da sustentabilidade, o crescente processo de transformação da sociedade, a democracia e a cidadania, o desenvolvimento regional deve ser visto como uma nova forma de conceber a vida em sociedade. Uma política de desenvolvimento somente será eficaz quando espelhada na realidade regional, amplamente conhecida e com os problemas e potencialidades identificados pela população. É preciso conhecer a fundo a realidade e propor ações respaldadas pela população.

Por outro lado, Dallabrida (2000, p. 188) enfatiza o que também é fundamental para o processo de desenvolvimento regional:

Uma ordenação sustentável do território é a que alia o ótimo para o homem com o adequado para a natureza, através de uma relação sociedade/natureza, harmônica e não predatória. Com isso teremos instituído um modelo de desenvolvimento sustentável, entendido, a priori, como aquele que leva em conta a pessoa humana, o econômico e o equilíbrio ambiental, a curto, médio e longo prazos. [...] É possível afirmar que a sustentabilidade tenha que ser construída a partir de experiências regionais, estando presente em todas as iniciativas de alavancagem do desenvolvimento. 
$\mathrm{Na}$ realidade mundial atual, sob o processo da globalização, é imprescindível que se considere a discussão de políticas regionais, a fim de se conhecer quais obstáculos precisam ser superados para a construção de um processo de desenvolvimento regional que atenda ao princípio da sustentabilidade.

O desenvolvimento territorial em zona rural resulta da composição de ações coletivas de atores locais, relações sociais e instituições que buscam soluções plausíveis para os problemas comuns neste espaço. Essas ações coletivas e cooperativas, frutos do dinamismo de seus atores, surgem como oportunidade inovadora para o desenvolvimento rural.

Schneider e Tartaruga (2004, p. 13) definem o desenvolvimento rural como:

\begin{abstract}
Um processo que resulta de ações articuladas que visam induzir mudanças socioeconômicas e ambientais no âmbito do espaço rural para melhorar a renda, a qualidade de vida e o bem-estar das populações rurais. Dadas as especificidades e particularidades do espaço rural, determinados pelos condicionantes sociais, econômicos, climáticos e tecnológicos, o desenvolvimento rural refere-se a um processo evolutivo, interativo e hierárquico quanto aos seus resultados, manifestando-se nos termos dessa complexidade e diversidade no plano territorial.
\end{abstract}

O desenvolvimento é um processo de construção coletiva que deve priorizar a redução da pobreza rural, estimular o intercâmbio dos atores locais entre si, a partir de redes, associações e cooperativas, e com o mundo externo, articulando junto ao poder público e/ou instituições. Privilegia-se a dinâmica de arranjos sociais de trabalho e produção, como estratégias produtivas de unidades familiares, bem como sua interação com os atores do território e externos a estes. Essa sinergia potencializa espaços, culturas e a própria interação com os mercados.

No caso da agricultura, o ponto de partida, segundo Schneider e Tartaruga (2004, p. 16), é “o agricultor, sua família, sua propriedade, sua atividade produtiva e as redes sociais e institucionais em que estiver inserido, que podem ser materiais ou intangíveis, ligadas à memória e às representações".

O processo de desenvolvimento regional deve ser planejado, promovido ou conduzido de acordo com os desejos e anseios locais, objetivando o desenvolvimento social, humano e sustentável, privilegiando, assim, a melhoria da qualidade de vida das gerações atuais e futuras.

O planejamento para o desenvolvimento deve envolver, em processo coletivo, a sociedade, o governo, as empresas e a população. As necessidades da população devem ser compreendidas, atendidas e priorizadas, considerando os recursos existentes.

\title{
4 Arranjos Produtivos como indutores do Desenvolvimento Regional
}

Em meio às inúmeras possibilidades apontadas para o alcance do desenvolvimento regional sustentável se encontram os Arranjos Produtivos Locais (APLs). 
Segundo Lastres e Cassiolato (2003, p. 3-4), os APLs são:

\begin{abstract}
aglomerações locais que contam com o envolvimento de agentes econômicos, políticos e sociais, que, com foco em atividades de um segmento econômico especifico, apresentam vínculos entre si, mesmo que incipientes. Essas aglomerações locais apresentam a participação e a interação entre empresas produtoras de bens de capital, serviços, fornecedoras de insumos e comercializadoras para os produtos da aglomeração. Contam ainda com outras organizações, públicas ou privadas, de apoio às atividades da aglomeração, tais como: empresas financeiras, entidades políticas, entidades de promoção, pesquisa e desenvolvimento, universidades e outras entidades para a formação e capacitação da mão de obra.
\end{abstract}

Muitos são os estudos sobre os APLs. Cabe às organizações de apoio desenvolver ações que contribuam para o desenvolvimento e consolidação do APL.

Lastres e Cassiolatto (2003, p. 4-5) desenvolveram estudos sobre os APLs, resultando na caracterização, segundo "1) a dimensão territorial; 2) a diversidade de atividades e atores econômicos, políticos e sociais; 3) o conhecimento tácito; 4) a inovação e aprendizado interativos; 5) a governança; e 6) o grau de enraizamento".

Lemos (2003, p. 81) definiu APLs como "aglomerações territoriais de agentes econômicos, políticos e sociais, com foco em um conjunto específico de atividades econômicas e que apresentam vínculos e interdependência". APLs são aglomerações de empresas de pequeno e médio porte, encontradas em uma mesma localidade, explorando o mesmo tipo de atividade econômica, apresentando uma especialização produtiva com certo grau de interação (troca de informações, relação de confiança), articulação, aprendizado e cooperativismo entre elas mesmas e com outros atores locais. Esses atores seriam o poder público e privado, representados por financiadoras, entidades de ensino e associações empresariais.

O que se percebe é que não há uma fórmula específica para se efetivar um arranjo produtivo local, pois cada um possui elementos particulares que variam conforme a região onde são implantados, porém, apresentam traços comuns entre eles. Esses traços se referem ao capital social (potencial para articulação coletiva, mercado e político-institucional) que compõe um território. O que, para Brandão et al. (2005, p. 2), "passa a ser como que o grande regulador de relações, encarnando projetos sociais".

Afirmam Witmann, Dotto e Boff (2003, p. 319) que:

Épocas e ambientes contextualizam práticas sociais balizadas em fontes paradigmáticas, que induzem a formação de estratégias e modelos diferenciados de desenvolvimento, permitindo a existência de elementos associados e/ou dissociados em relação ao global, regional e local. 
No conjunto global, o que se percebe é que, por meio da competitividade criativa, essas práticas aumentam a eficácia e quebram barreiras impostas pelo mercado que exige uma produção em grande escala.

Brandão (2004) propõe uma gestão estratégica para o território, que deve buscar delinear seus cursos apropriados de ação, posicionamento sustentável, identificação de foco e competência, potencializar fatores endógenas e pensar "realisticamente" sobre o futuro.

Para Sachs (1986), o desenvolvimento regional endógeno deve ser constituído dos seguintes elementos: capacidade cultural de pensar-se a si próprio e inovar, capacidade político-administrativa de tomar decisões autônomas e organizar a execução das mesmas.

No que tange ao desenvolvimento regional, esse está calçado em modelos e fatores integrados, os quais tendem a potencializar uma região, como cultura, diferentes formas de associativismo, arranjos organizacionais e capital social.

De acordo com Galvão e Vasconcelos (1999, p. 5), na diagnose ou proposição de políticas de desenvolvimento regional, duas questões devem ser analisadas:

\begin{abstract}
A primeira é se os atores e estruturas sociais de um lugar ou porção territorial estão plugados ou não às redes internacionais $\mathrm{e}$, se, portanto, encontram boas condições de reprodução. A segunda é se essas conexões fundam-se ou não em um conjunto de virtudes socioeconômicas especiais no âmbito das relações sistêmicas presentes nas articulações socioprodutivas relevantes em clusters específicos.
\end{abstract}

Esses arranjos devem ocorrer naturalmente, estimulando a criatividade. Não devem ser induzidos, o que geralmente acontece com o envolvimento do Estado, o qual estimula a existência de estratégias externas ao ambiente em questão. Porém, este deve ser um mediador, priorizando o equilíbrio entre os agentes e os locais que o integram.

O Estado deve intervir, enquanto agente pró-ativo, na solução de problemas em que os agentes locais não possuam instrumentos e autonomia para a sua resolução, direcionando, dessa forma, a localidade para uma trajetória social mais promissora, no longo prazo. Brandão et al. $(2005$, p. 20) destacam que:

\begin{abstract}
Uma ação pública eficiente deve desenvolver a sustentabilidade do APL capaz de manter a trajetória de desenvolvimento do aglomerado sustentada; promover a elevação do capital social, por intermédio de ações que favoreçam a inclusão dos agentes estabelecendo relações de confiança; democratizar o acesso aos bens públicos [...] através do aumento da oferta; preservar o meio ambiente através de ações de preservação e controle dos impactos ambientais e mobilizar os recursos endógenos por meio da articulação.
\end{abstract}

Cabe ao poder público cumprir o papel-chave nesse processo. Deve estar bem capacitado, com recursos materiais e humanos para incentivar a democracia, 
garantindo transparência, acompanhamento, fiscalização e o monitoramento permanente, além do papel decisivo de impor e fazer cumprir sanções e benefícios. Seria o Estado, assim, o condutor do processo de desenvolvimento sustentável, coadjuvado pelos agentes locais.

\section{Agregação de valor à Agricultura Familiar}

Dados levantados pelo Censo Agropecuário (Instituto Brasileiro de Geografia e Estatística - IBGE, 2006) mostram que o Estado de Santa Catarina é composto por 193.663 estabelecimentos agropecuários, totalizando uma área de 6.040.134 ha. O mesmo levantamento demonstra, por sua vez, que desse total de estabelecimentos agropecuários, 38\% possuem menos de 10 ha e $42,5 \%$ possuem de 10 a menos de 50 ha. (IBGE, 2006). Desse total, 168.000 estabelecimentos praticam a agricultura familiar, o que faz de Santa Catarina uma das unidades da federação com maior percentual de agricultores familiares do Brasil, o que faz do Estado uma referência nacional e internacional.

Pela Lei 11.326, de 24/07/2006, considera-se agricultor familiar e empreendedor familiar rural aquele que pratica atividades no meio rural, atendendo, simultaneamente, aos seguintes requisitos:

\footnotetext{
I - não detenha, a qualquer título, área maior do que 4 (quatro) módulos fiscais;

II - utilize predominantemente mão de obra da própria família nas atividades econômicas do seu estabelecimento ou empreendimento III - tenha renda familiar predominantemente originada de atividades econômicas vinculadas ao próprio estabelecimento ou empreendimento; e

IV - dirija seu estabelecimento ou empreendimento com sua família.
}

Estima-se que a agricultura familiar represente aproximadamente $86 \%$ da população rural, e ocupe $80 \%$ da área dos estabelecimentos agrícolas no estado de Santa Catarina (Secretária de Estado da Agricultura e da Pesca, 2011).

Este cenário apresenta, portanto, a importância de encontrar alternativas viáveis e sustentáveis para esses estabelecimentos, considerando o montante de pessoas envolvidas e a sobrevivência das mesmas.

Uma das alternativas viáveis para o fortalecimento da agricultura familiar é a agregação de valor às propriedades rurais. De acordo com Batalha e Souza Filho (2005, p. 15), isto pode ocorrer de várias formas:

As principais estão relacionadas ao desenvolvimento e à comercialização de produtos que destaquem características como o caráter social da agricultura familiar, a territorialidade do local onde os produtos são fabricados, e o sabor diferenciado originado de alguma característica artesanal do processo produtivo. 
Nesse direcionamento destaca-se o processo das agroindústrias artesanais, as quais apresentam tamanhos e características diferentes umas das outras. Cada qual possui métodos e critérios distintos na sua formação. A agroindústria que será debatida aqui será a de pequeno porte, que possui mão de obra familiar denominada de agroindústria familiar. Essa é uma unidade de produção que transforma, de forma artesanal, o produto in natura e o comercializa diretamente ao consumidor ou em mercados locais e/ou regionais.

Para o Banco de Desenvolvimento Regional do Extremo Sul (BRDE, 2004, 5) a agroindústria é uma:

Atividade que permite aumentar e reter, nas zonas rurais, o valor agregado da produção da agricultura familiar, através da execução de tarefas pós colheita nos produtos provenientes de explorações agrossilvipastoris, tais como, seleção, lavagem, classificação, armazenamento, conservação, transformação, embalagem, transporte e comercialização.

A agroindústria é mais uma oportunidade para superar as inúmeras dificuldades enfrentadas pelos agricultores quanto à sua permanência no meio rural. Uma família rural que se dedica à cultura da banana pode agregar novos ganhos com a transformação da bananeira em fibras, com a transformação da banana em musse de banana, em farinha de banana para a fabricação subsequente de balas. Pode ainda com o cultivo da cana-de-açúcar, produzir o melado e com ele schmier ou, ainda, açúcar mascavo. Com os excedentes podem produzir conservas de pepinos, beterrabas, repolhos e cenouras. Fabricar pães, quitutes, bolos, tortas, utilizando aipim, cará e batata-doce. Com uso do leite, produzir a schmier, assim como da mandioca extrair a farinha de mandioca e o polvilho, e, com os cultivares de palmitos e palmáceas, produzir conservas envasadas (ALVES e SAMPAIO, 2014).

Agroindustrialização é compreendida como elaboração de produtos artesanais comestíveis de origem animal e vegetal, no qual o processo utilizado na obtenção de produtos não descaracterize aspectos tradicionais, culturais ou regionais, produzidos em pequena escala, obedecidos os parâmetros fixados em regulamento (BRASIL, 1997).

Como cada propriedade rural trata-se de um caso específico, ela poderá organizar-se em torno do que produz e diversificar sua produção, a fim de preencher o tempo disponível com essas novas atividades, que podem integrar, além da agroindústria artesanal, a produção de produtos orgânicos e o desenvolvimento do agroturismo como atividades geradoras de trabalho e renda.

A produção de produtos orgânicos apresenta-se como alternativa importante, diante da demanda por alimentos mais saudáveis, sem substâncias químicas prejudiciais à saúde.

Para Cerveira \& Castro (1999, p. 12), “o motivo determinante das opções dos consumidores que estão reorientando seu consumo para os produtos orgânicos não é, primordialmente, a preocupação com a conservação do meio ambiente, [...] mas sim a atenção com a saúde". Isso pode sugerir que a 
racionalidade individual se sobrepõe à coletiva, característica esta da chamada modernidade e que se mantém, conforme Harvey (1994), na pós-modernidade

A produção de orgânicos pode ser uma alternativa econômica para a sustentabilidade econômica da agricultura familiar e que produz bons resultados, conforme cita Abramovay (1999, p. 10):

\begin{abstract}
A exportação da soja gaúcha com um selo garantindo que ela é "orgânica" e não contém produtos transgênicos - que conta com o apoio de algumas Organizações Não Governamentais - pode elevar seu valor em até $80 \%$. O mesmo ocorre com o café orgânico no Sul do Estado de Minas Gerais, exportado pelo dobro do preço do produto convencional para a Alemanha.
\end{abstract}

Porém, esse processo é moroso, pois há um período de transição ou de conversão para produção orgânica de base agroecológica, o que acaba sendo oneroso para o pequeno agricultor rural, mesmo que tenha havido pouco uso de intensivos agrícolas químicos (ASSIS, 2002).

Outra forma de agregação de valor é a exploração da atividade turística em suas várias modalidades.

Para Grünewald (2003, p. 141), o turismo indica:

\begin{abstract}
Movimento de pessoas que não estão a trabalho em contextos diferentes do de origem, seja este o lar, a cidade ou o país. Trata-se, geralmente, de visitação a lugares onde poderão ser desempenhadas as mais variadas formas de atividades práticas e/ou subjetivas desde que não o trabalho.
\end{abstract}

O turismo é uma atividade que envolve a dimensão social, econômica e ambiental do desenvolvimento, promovendo interação dos visitantes com os anfitriões, gerando riquezas que são fundamentais para a agricultura familiar. Para tanto, deve-se levar em conta a participação da comunidade, especificidades e potencialidades de cada localidade para eleger, dentro dos diversos tipos de turismo, o que mais se adapta às propriedades agrícolas.

Os modos de vida do agricultor (seus modos de produção e de conhecimento) se tornam o principal atrativo para a atividade de turismo. Mas, se faz necessário atender, de forma criativa, a demanda, porém de maneira consciente e sustentável.

Uma forma específica de interagir no espaço rural é o agroturismo. De acordo com Tulik (2003, p. 39), o agroturismo:

se desenvolve integrado a uma propriedade rural ativa, de organização e gestão familiar, com a presença do proprietário, como forma complementar de atividades e de renda; pressupõe contato direto do turista com o meio rural, alojamento na propriedade e possibilidade de participar das atividades rotineiras. 
Este é visto como forma de desenvolvimento para as áreas rurais, pois gera desenvolvimento social e econômico, estimulam a preservação das áreas naturais, tradições e cultura das famílias rurais, elementos essenciais para despertar nas pessoas que vivem no meio urbano o interesse pela vida rural. Com o agroturismo, agricultores têm a oportunidade de comercializar alimentos saudáveis, oferecendo o slogan da vida singular que é o diferencial do meio rural.

\section{Projeto "Valorizar o Artesanal"}

Guaramirim situa-se ao Sul do Brasil, Norte de Santa Catarina, entre três polos regionais que são Joinville, Jaraguá do Sul e Blumenau. É cortada por duas importantes rodovias, SC-413 e BR-280, por onde passam aproximadamente 22.000 pessoas diariamente. Está situada próximo ao litoral, conforme pode ser visualizado na Figura 01. Possui 35.186 habitantes. A área rural do município é formada por pequenas propriedades agrícolas familiares que praticam diversas culturas. No entanto, há predomínio da monocultura do arroz irrigado, e da policultura, como cana de açúcar, mandioca, banana, milho, olerículas, palmeira real, bananas, avicultura de corte, piscicultura, gado de corte e leite e produção de mel (PMG, 2013).

Guaramirim apresenta realidade que não é única no cenário brasileiro. Agricultores estão comercializando suas terras e se transferindo para o meio urbano em busca de novas formas de sobrevivência. Alguns até permanecem; porém, seus sucessores não. Em alguns casos até residem na área rural, mas a propriedade perde sua função produtiva, transformando-se em residência, e a renda e o trabalho passam a ser provenientes do espaço urbano.

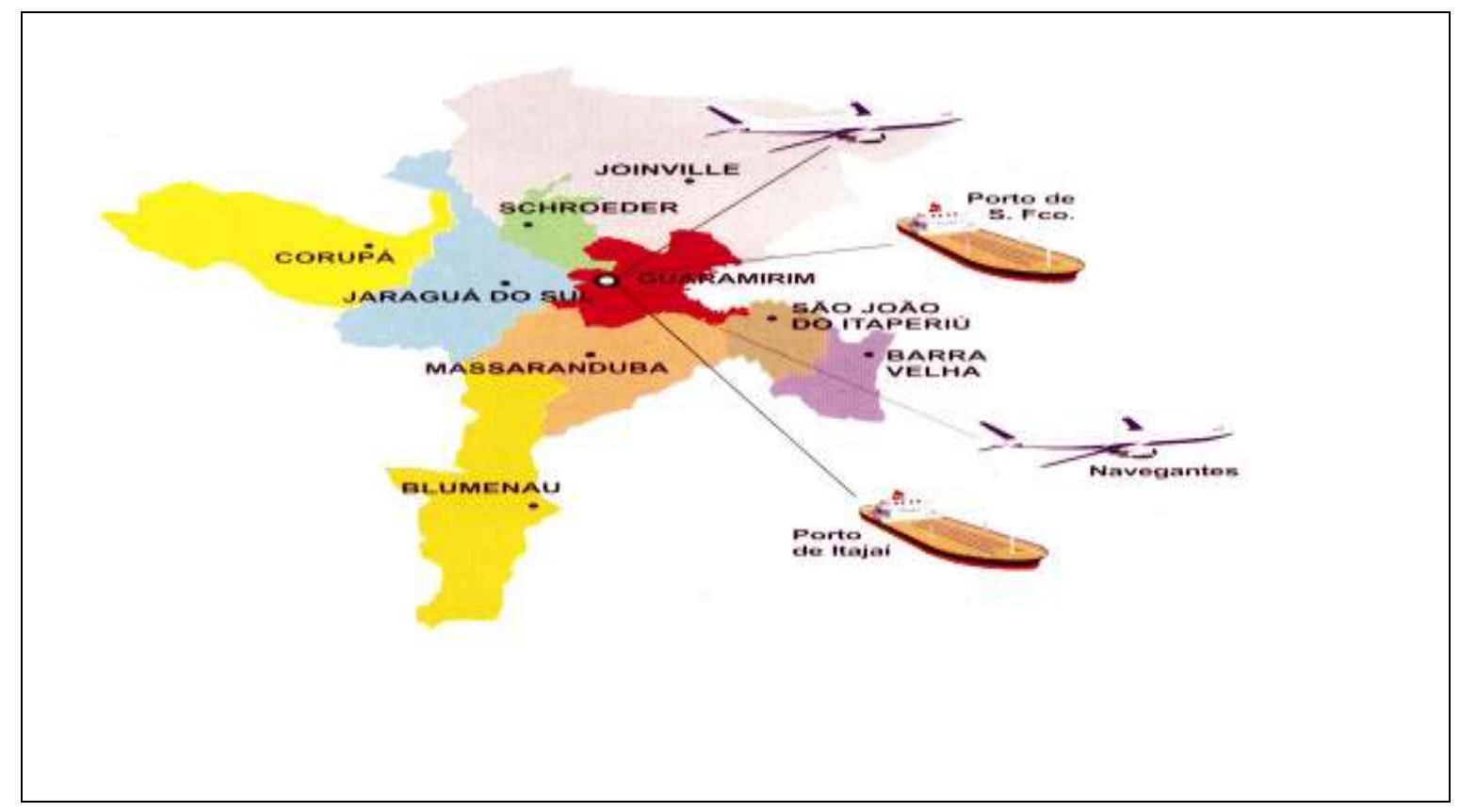

Figura 1. Mapa da localização do Município de Guaramirim Fonte: PMG (2013). 
Frente às dificuldades e aos desafios encontrados junto a agricultores de Guaramirim interessados em permanecer no campo, conforme apresentado anteriormente, criou-se o Projeto "Valorizar o Artesanal", que teve como principal motivação a agregação de valor à propriedade rural.

Não havia até então no município pequenos produtores artesanais regularizados com unidades de produção que cumprissem as normativas de órgãos reguladores e que utilizassem da prática da gestão de negócios. Prova disso eram as denúncias recebidas pela prefeitura, como falta de qualidade dos produtos e o risco que esses ofereciam à saúde pública, no caso da ocorrência de uma Doença Transmitida por Alimentos, chamada por DTA ${ }^{2}$. Os agricultores produziam seus produtos em suas próprias cozinhas. Segundo a vigilância sanitária, o ideal seria que cada propriedade tivesse uma unidade de produção própria ou associada, questão essa que se sabe de difícil solução, diante do custo que disso decorre.

A partir de estudo da prefeitura municipal, havia tendência de mercado para compra de produtos artesanais, e que tivessem identidade com o modo de vida rural. Normalmente esses produtos são produzidos em pequena escala, o que sugere agregação de valor para incrementar a renda da pequena propriedade rural, que, consequentemente, aumenta as possibilidades de permanência do homem no campo.

\subsection{Descrição do Projeto}

Foram beneficiados pelo Projeto agricultores familiares do município de Guaramirim. O principal parceiro da administração municipal de Guaramirim é a Empresa de Pesquisa Agropecuária e Extensão Rural de Santa Catarina SA (EPAGRI).

Constituiu-se uma comissão com funções que abrangessem acompanhamento dos produtores, com constantes visitas, capacitação sobre noções básicas de higiene para fabricação e manipulação segura dos alimentos, legislação, processamento e embalagem, fornecimento de rótulos para os produtos e produção de novas receitas, além de orientação técnica, missões de trabalho e visitas a outros municípios, acolhimento de excursões de turismo e divulgação nos meios de comunicação. Quanto à fiscalização, houve medidas preventivas, como análise de laboratório de produtos e regras de exclusão, quando havia descumprimento de orientações da vigilância sanitária, colocando em risco a saúde pública $e$, consequentemente, todo o conjunto de produtos que integram o projeto. Quanto à implementação, definiram-se etapas e prazos para adequação, orientações para a obtenção de recursos financeiros, bem como auxilio para cálculo de custos, prática da administração das propriedades rurais e a confecção de placa de identificação da propriedade.

A legalização dos produtos fabricados artesanalmente pelos agricultores obedece à legislação vigente (BRASIL, 2006). Dessa forma, possibilita-lhes

${ }^{2}$ DTA apresenta frequentemente sintomatologias próprias, como náuseas, vômitos ou febre. Muitas pessoas desconhecem se a enfermidade é causada por bactéria ou outro patógeno em alimentos. 
comercializar os produtos de forma ordenada, porém, apenas no município de Guaramirim. Para tanto, se fez necessário que esses agricultores fizessem parte de uma cooperativa com número mínimo de 20 integrantes. Fazem parte desse processo de legalização e agregação de valor ao produto: embalagens, qualidade, padronização, comprometimento na entrega e rótulo.

O projeto estimulou a prática de ações integradas entre agricultores, prefeitura e órgãos estaduais, buscando a organização social, associação e cooperação, a partir das competências e identidades culturais dos agricultores, bem como a capacidade de gestão desses, sob a perspectiva do desenvolvimento territorial sustentável.

\subsection{Resultados do Projeto}

Esta seção apresenta os resultados socioeconômicos, culturais e ambientais da implantação do projeto "Valorizar o Artesanal".

Sob a dimensão socioeconômica, houve aquisição de novas áreas de terra, ampliando as propriedades; melhorias nas residências e nas instalações das propriedades rurais, tanto na ampliação quanto em reformas; aquisição de novos equipamentos de produção, automotores como carro, motocicleta e trator; e utensílios eletrônicos, a exemplo de eletrodomésticos, linha telefônica e celular. Houve geração de novos postos de trabalho, na agroindustrialização de produtos até então comercializados in natura. Além da capacitação dos agricultores a partir de cursos, informações e adequações na prática do trabalho, sobretudo na melhoria da administração das propriedades rurais, potencializando espaços anteriormente não utilizados ou subutilizados na produção.

Quanto à agregação de valor à produção, no que concerne à dinâmica da cadeia produtiva da agricultura familiar, o que era até então excedente de produção agrícola, transformou-se em insumo na agroindustrialização em pequena escala, como a cana-de-açúcar originando o melado e outros derivados, processamento de frutas transformando-se em geleias e doces, verduras e legumes sendo produzidas como conservas, aipim e batata doce usados na fabricação de pães e doces, leite em queijos, por sua vez, em strudel. Cabe ressaltar que o descarte na seleção de insumos transformou-se em ração animal. Diversificaram as culturas, anteriormente caracterizadas pela monocultura, como anteriormente assinalado, ocorrendo aumento da produção a partir de novos manejos.

Para demonstrar o quanto agrega valor à produção in natura, observa-se a Tabela abaixo: 
Tabela 1. Agregação de Valor à Produção in natura

\begin{tabular}{|c|c|c|c|}
\hline $\begin{array}{c}\text { Comercialização } \\
\text { in natura de } 300 \text { gramas } \\
\text { de pepino }\end{array}$ & $\begin{array}{c}\text { Transformado } \\
\text { artesanalmente em } \\
01 \text { vidro }\end{array}$ & $\begin{array}{l}\text { Custo da industria- } \\
\text { lização }\end{array}$ & Lucro \\
\hline$R \$ 0,30$ & $R \$ 1,50$ & $R \$ 0,90^{*}$ & $R \$ 0,60$ \\
\hline
\end{tabular}

Fonte: Radwanski, (2009).

Outro ponto a ser considerado é que o produto in natura, muitas vezes, corre o risco de não ser comercializado ou vendido a preços condizentes. A transformação é também uma segurança para o agricultor que ganha maior remuneração e mais tempo para comercializar o produto, pois se aumenta a durabilidade e, consequentemente, o prazo de validade do produto.

O projeto oportuniza a comercialização de um produto transformado, utilizando o "saber fazer dos agricultores", adaptando à cultura dos antepassados, que vem sendo passada de geração a geração, às exigências atuais de adequação, mercado, concorrência, etc. O produto torna-se seguro, sob o ponto de vista alimentar e legal, sob a ótica de tributos, mantendo as mesmas características de produto artesanal. Assim, o projeto prioriza e incentiva o modo artesanal de produzir e valoriza socioculturalmente o modo de vida rural.

Essa comercialização exige adequação à legislação sanitária, considerada até o momento de sua adequação como ponto negativo do projeto, e que passou a valorizar os produtos, tornando-os mais seguros dentro do conceito de higiene e limpeza aos olhos dos consumidores, o que possibilitando maior e melhor comercialização.

Não que o produtor desconhecesse o processo de fabricação, através do Projeto acabou compreendendo os pormenores de todo o ciclo do seu produto, desde o plantio até o mercado consumidor.

O agricultor, que anteriormente comercializava muitas vezes para apenas um comprador, depois de se inserir no projeto, ampliou o número de consumidores interessados, incrementando sua renda. Dessa forma, não precisou mais ter dupla jornada de trabalho, normalmente como diarista em propriedades vizinhas ou, então, como trabalhador na indústria.

O que se constata é que os agricultores participantes do projeto decidiram que a atividade agrícola e a pluriatividade rural, tal como agroturismo e agroindústria, seriam atividades priorizadas por eles, não tanto pelo bucolismo ou romantismo que a agricultura sugere, mas, sobretudo, porque se identificam como agricultores e desejam permanecer no campo, por ser este seu modo de vida, produção e conhecimento. O que lhes faltavam eram oportunidades para, assim, se manterem trabalhando (Entrevistado 06).

Outro incremento proporcionado pelo projeto foi a capacitação dos agricultores quanto à administração se suas propriedades, no entanto com significado de socioempreendedorismo, isto é, como um agricultor com identidade no campo. Esta capacitação os levou a reconhecer a importância da utilização de 
antigas e novas práticas, tecnologias que se fazem mais apropriadas, mais associadas à segurança alimentar, desassociadas da agroindústria mecanizada.

Os agricultores que participaram do projeto sentem-se privilegiados por garantirem sua reprodução social, e a possibilidade de permanência de seus filhos também na propriedade, como agricultores ou realizando tarefas na cadeia por ela desencadeada, legalizada, o que era mais difícil anteriormente ao projeto (Entrevistado 06).

Quanto à dimensão ambiental ou, melhor, socioambiental, o Projeto é considerado como estratégia de desenvolvimento territorial sustentável, pois, enquanto valoriza o capital social das comunidades, estimulando a cooperação e articulação entre os agricultores e com suas entidades representativas (Entrevistado 3), também proporciona uma tomada de consciência mais qualificada em relação ao uso e manejo dos recursos naturais. Contudo, há graus distintos de tal consciência, desde a disposição correta de resíduos e a utilização de agrotóxicos de forma racional: "Uso só o recomendado" (Entrevistado 12), até descaso com o meio ambiente: "Levei sorte, consegui tirar todo o mato antes dessa lei", referindo-se ao código florestal do Estado de Santa Catarina (Entrevistado 13).

O uso de defensivos agrícolas químicos sintetizados, muitas vezes estimulado por órgãos governamentais de apoio à agricultura, contrapõe aos modos de conhecimento da pequena agricultura familiar, com práticas mais apropriadas aos ecossistemas locais. $\mathrm{Na}$ ocasião em que há falta de orientação técnica, os agricultores utilizam esses defensivos de forma inadequada.

Neste sentido, as propriedades rurais sob a perspectiva da dinâmica agroecossistêmica, como sugere o Projeto, acabam criando alternativas, como culturas associadas, possibilidade de acesso ao mercado de orgânicos, prática do turismo comunitário, princípio da multifuncionalidade ${ }^{3}$ e o recente mercado de créditos de carbono ${ }^{4}$. Esse conjunto de esforços agrega valor às propriedades, como anteriormente dito, e ainda preserva a biodiversidade territorial.

\section{CONCLUSÕES}

Enfim, o Projeto "Valorizar o Artesanal" cria novas oportunidades para agregar valor à produção oriunda da pequena propriedade rural do município de Guaramirim, anteriormente limitada na maioria das vezes na comercialização do produto "in natura", o que fomenta incremento econômico e ocupa mão de obra familiar, além de gerar postos de trabalho para terceiros. Em relação a este último

\footnotetext{
${ }^{3}$ Multifuncionalidade significa oferta de serviços e atividades humanas, agricultura e pesca que não apenas se resumem em função produtiva, mas oportunizam funções de conservação da natureza, inclusive de preservação, no território (RÉMY, 2010).

${ }^{4}$ Os Créditos de Carbono são certificados gerados por projetos que, comprovadamente através de metodologias, reduzam ou absorvam emissões de gases do efeito-estufa. Os compradores destes créditos são empresas ou governos de países desenvolvidos que precisam alcançar metas (instituídas pelo Protocolo de Quioto, pela própria empresa ou por outros programas) de redução destas emissões, e os vendedores são diversificados dependendo do país de origem do projeto (SAMPAIO, LESAMA, ARAÚJO, 2012).
} 
tópico, há receio em fazê-lo, em razão dos encargos trabalhistas computados quando da legalização desses funcionários.

Há que ressaltar que os resultados do Projeto não podem ser apenas mensurados por indicadores socioeconômicos melhores, mas também pela melhor qualificação no processo de tomada de decisão, quando o poder público e as entidades envolvidas na implantação do projeto discutem e definem, em parceria com os agricultores, tanto os problemas como as alternativas de solução desses. Destaca-se o atendimento à legislação sanitária, tema que normalmente inviabiliza unidades de produção familiares ou, então, as chamadas cozinhas comunitárias.

Entretanto, há desafios a serem superados na implantação do projeto, como falta de articulação e ausência de espírito coletivo, o que dificulta a formação de cooperativas e associações. Ausência de incentivos financeiros para o fomento produtivo e assistência técnica específica, como orientação sobre o manejo do solo e de dejetos agrotóxicos. As vias de acesso são deficitárias e não há local adequado para comercialização dos produtos, tais como feiras. A falta de telefonia e de programa de educação quanto aos riscos que oferecem os produtos fora das conformações sanitárias, compromete a segurança alimentar.

A prática de gestão é construída a partir de uma metodologia participativa, na qual se insere as singularidades da dinâmica territorial de Guaramirim no trato regional, denominadas por capital social. O desafio é criar arranjos socioprodutivos e políticos locais que integram as espacialidades rurais e urbanas, no sentido de ressaltar suas complementaridades e não as suas diferenças, como vem se realizando nas estratégias de identificação geográfica, nas quais ressignificam os territórios a partir das relações entre as esferas de produção e consumo.

Estabelecer arranjos envolve transferência de aprendizado, cooperação, inovação e articulação dos atores envolvidos, tornando-se assim núcleos de desenvolvimento setorial local e regional. Além da diversificação, as propriedades iniciaram a prática da "especialização", principalmente com produtos que possuem problemas com as intempéries climáticas, como, por exemplo, o pepino, que é produzido com temperaturas altas: durante o inverno, o agricultor planeja produzi-lo com tecnologia apropriada com a técnica de cultivo protegido, as conhecidas "estufas".

E dentre as novas possibilidades, pode-se citar o processo de agregação de valor promovido pelo Projeto "Valorizar o Artesanal", pois estimula, não somente a transformação do produto in natura, mas também a prática de outras atividades, como por exemplo: exploração da atividade de turismo em suas várias modalidades. É um processo de agregação de valor aos bens e serviços oferecidos pela propriedade agrícola. O agricultor explora o pesque-pague, não somente vendendo os peixes que são pescados, mas preparando-os para que sejam consumidos ali mesmo na propriedade ou vendidos congelados. O agricultor agrega aos produtos comercializados não somente o fator qualidade, pelo fato de ser um produto natural, mas também o próprio modo de vida que é seu patrimônio cultural.

Conclui-se que o Projeto "Valorizar o Artesanal", implantado em Guaramirim (SC), configura-se como estratégia de desenvolvimento territorial sustentável na ocasião em que agricultores administram suas propriedades como 
sócios empreendedores, conciliando viabilidade na economia de mercado e ao mesmo tempo sua identidade no campo, reconhecendo a importância de seus modos de vida, de sua produção e de seu conhecimento, desfazendo-se dos encantos da vida urbana, como se não houvesse qualidade de vida no mundo rural. Eles que decidam se desejam ser pequenos ou grandes empreendedores.

\section{REFERÊNCIAS}

ABRAMOVAY, R. O capital social dos territórios: repensando o desenvolvimento rural. Economia Aplicada, v. 4, n. 2, p. 379-397, 2000.

ABRAMOVAY, R. Agricultura familiar e desenvolvimento territorial. Revista da Associação Brasileira de Reforma Agrária, v. 28, n. 1, jan/ago 1999.

ALVES, F. K..; SAMPAIO, C. A. C. Arranjo socioprodutivo de base comunitária (apl.com): um projeto piloto na comunidade do entorno da Microbacia do Rio Sagrado (Morretes/PR). Organizações Rurais \& Agroindustriais, Lavras, v. 15, n. 1, p. 30-42, 2013.

ASSIS, R. L. de. Agroecologia no Brasil: análise do processo de difusão e perspectivas. 2002. 150 p. Tese (Doutorado em Economia Aplicada), Universidade Estadual de Campinas, Campinas. 2002

BASSAN, D. S.; SIEDENBERG, D. R. Desenvolver buscando a redução das desigualdades. IN: BECKER, D. F.; WITTMANN, M. L. Desenvo/vimento regional: abordagens interdisciplinares. Santa Cruz do Sul: EDUNISC, 2003.

BATALHA, M. O.; SOUZA Fo, H. M. O sistema agroindustrial de carnes no Brasil: principais aspectos organizacionais. Grupo de estudos e pesquisas agroindustriais. Departamento de Engenharia de Produção - UFSCar. São Carlos. 2005. Relatório.

BRANDÃO. C. A. Teorias, estratégias e políticas regionais e urbanas recentes: anotações para uma agenda do desenvolvimento territorializado. Revista Paranaense de Desenvolvimento, n.107, p. 55-74, Curitiba, jul/dez. 2004.

BRANDÃO, C. A.; COSTA, E. J. M.; ALVES, M. A. Estratégias de desenvolvimento e a construção do espaço supra local: os novos arranjos institucionais. XI Encontro Nacional da Associação Nacional de Pós-Graduação em Planejamento Urbano e Regional-ANPUR. Salvador, 23 a 27 de Maio de 2005. Anais ..., Salvador, 2005.

BRASIL, Lei 10.610, de 01 de dezembro de 1997. Estabelece as diretrizes para a formulação da Política Nacional da Agricultura Familiar e Empreendimentos Familiares Rurais. Diário Oficial da República Federativa do Brasil, Brasília, DF, n. 141, 25 dez. 2006 Seção 1, p.1.

BRASIL, Lei no 11.326, de 24 de julho de 2006. Estabelece as diretrizes para a formulação da Política Nacional de Agricultura Familiar e Empreendimentos 
Familiares Rurais. Diário Oficial da República Federativa do Brasil, Brasília, DF, 25 jul. 2006. p. 1, col. 2.

BRDE, Banco de Desenvolvimento Regional do Extremo Sul. Redes de agroindústria de pequeno porte: experiências de Santa Catarina. Florianópolis, 2004.

CERVEIRA, R.; CASTRO, M.C. de. Consumidores de produtos orgânicos da cidade de São Paulo: características de um padrão de consumo. Informações Econômicas, v. 29, n.12, p.7-20, 1999.

DALLABRIDA, V. R. Sustentabilidade e endogenização: novos paradigmas para o desenvolvimento regional. IN: BECKER, D. F.; BANDEIRA, P. S. Determinantes e desafios contemporâneos. Santa Cruz do Sul: EDUNISC, 2000.

FRANCO, A. Porque precisamos desenvolvimento local integrado e sustentável. Brasília: Instituto de Política, 2000.

GALVÃO, A. C.; VASCONCELOS, R. Política regional à escala sub-regional: uma tipologia territorial como base para um fundo de apoio ao desenvolvimento regional. Brasília: IPEA, Texto para Discussão n. 665, 1999.

GUZZATI, T. C., TURNES, V., SAMPAIO, C. A. C. Novas relações entre agricultores familiares e consumidores: perspectivas recentes no Brasil e na França. Revista DAE, v.16, p.25 - 45, 2014.

HARVEY, D. Condição pós-moderna. São Paulo: Edições Loyola, 1994.

HOFF, K.; STIGLITZ, J. Modern economic theory and development. IN: MEIER, G. M.; STIGLITZ, J. E. (eds.). Frontiers of development economics: the future in perspective. Washington: World Bank Publications, 2001.

GRÜNEWALD, R. de A. Turismo e etnicidade. Horizontes antropológicos, v. 9, n. 20, p. 141-159, out, 2003.

INSTITUTO BRASILEIRO DE GEOGRAFIA. Censo agropecuário 2006. Rio de Janeiro: IBGE, 2009.

LASTRES, H. M. M.; CASSIOLATO J. E. Glossário de arranjos e sistemas produtivos $e$ inovativos locais. Rio de Janeiro: Sebrae, 2003.

LEMOS, C. Micro, pequenas e médias empresas no Brasil: novos requerimentos de políticas para a promoção de sistemas produtivos locais. Tese (Doutorado em Ciências). Instituto Alberto Luiz Coimbra de Pós-Graduação e Pesquisa de Engenharia (COPPE), da Universidade Federal do Rio de Janeiro. 2003.

PMG, Prefeitura Municipal de Guaramirim. Guaramirim naturalmente estratégico. Guaramirim: Prefeitura Municipal de Guaramirim, 2013 
PONTES, B.M.S. A contribuição do pensamento geográfico brasileiro à região e à regionalização vistas como processo. Boletim de Geografia Teorética, v.16, n.1 (31-34), p. 324-327,1986-1987.

RADWANSKI, E. M. Agregação de valor às propriedades rurais como alternativa de sustentabilidade: estudo de caso: a proposta do projeto "valorizar o artesanal" no município de Guaramirim (SC). Dissertação (Mestrado em Desenvolvimento Regional). Centro de Ciências Humanas e da Comunicação, da Universidade Regional de Blumenau. 2008.

RÉMY, J. A agricultura multifuncional a serviço do desenvolvimento sustentável? IN: VIEIRA, P. F.; CAZELLA, A.; CERDAN, C.; CARRIERE, J.-P. Desenvolvimento territorial sustentável no Brasil. Florianópolis: APED, SECCO, 2010.

SACHS, I. Espaços, tempos e estratégias de desenvolvimento. São Paulo: Vértice, 1986.

SCHNEIDER, S.; TARTARUGA, I. G. P. Território e abordagem territorial: das referências cognitivas aos aportes aplicados à análise dos processos sociais rurais. Revista de Ciências Sociais, v. 23, n. 01 e 02, p. 99-117, jan-dez, 2004.

SAMPAIO, C. A. C., LESAMA, M. F., ARAUJO, J. R. Possibilidades para pensar um arranjo socioprodutivo e político de base comunitária, solidária e ecologicamente sustentável no litoral paranaense In: PHILIPHI Jr., A.; SAMPAIO, C. A. C.;

FERNANDES V. Gestão de natureza pública e sustentabilidade.1 ed.Barueri (SP) : Manole, 2012, p. 891-924.

SANTA CATARINA, Secretária de Estado da Agricultura e da Pesca. SC RuralCooperação para o Desenvolvimento Rural. Disponível em

http://www.microbacias.sc.gov.br/visualizarNoticia.do?entity.noticiaPK.cdNoticia $=5106$. Acesso em 22/08/2011.

SILVA, J. G. da. O novo rural brasileiro. Campinas: UNICAMP, 1998. Disponível em http://www.ipea.gov.br/. Acesso em: 28 set 2005.

TULIK, O. Agroturismo. In: Turismo rural. São Paulo: Aleph, 2003.

VASQUEZ-BARQUERO, A. Crecimiento endógeno o desarrollo endógeno?, Cuadernos del CLAEH,p. 78-79, 1998.

WITTMANN, M. L.; DOTTO, D. M. R.; BOFF, V. A. Desenvolvimento regional: abordagens interdisciplinares. Santa Cruz do Sul: EDUNISC, 2003. 


\section{Sobre os autores \\ Elvira Maria Radwanski}

Mestra em Desenvolvimento Regional. Especialista em Gestão de Empreendimentos Turísticos. Agente Administrativo na Prefeitura Municipal de Guaramirim/SC. Áreas de Interesse:

Desenvolvimento Territorial; Agricultura Familiar; Agroturismo

Endereço: Rua Fritz Paul Techentin, Havai, CEP 89270-000 Guaramirim (SC)

E-mail: Elviramaria10@gmail.com

\section{Carlos Alberto Cioce Sampaio}

Pós-Doutor em Ecossocioeconomia/UACH e Cooperativismo Corporativo/U.Mondragón Professor do Curso de Turismo e Pós-Graduação em Gestão Urbana/PUCPR e em Desenvolvimento Regional/FURB. Colaborador do Mestrado em Desenvolvimento à Escala Humana e Economia. Ecológica/UACH. Coordenador Adjunto da Área de Ciências Ambientais/CAPES. Pesquisador CNPq. Áreas de Interesse: Ecossocioeconomia Urbana; Arranjo Institucional e Socioprodutivo de base Territorial; Turismo Comunitário, Solidário e Sustentável.

Endereço: Rua Vereador Washington Mansur, 248 apt 61 Ahú 80.540-210 Curitiba (PR) E-mail: carlos.cioce@gmail.com.br

\section{Maria do Carmo Martins Sobral}

Doutora e Pós-Doutora em Planejamento e Tecnologia Ambiental/U.Técnica da Berlin Professora do Curso de Graduação e de Pós-Graduação em Engenharia Civil e da Pós-Graduação em Desenvolvimento e Meio Ambinete-PRODEMA/UFPE. Coordenadora da Área de Ciências Ambientais/CAPES. Pesquisadora CNPq. Áreas de Interesse: Planejamento Ambiental; Avaliação de Impacto Ambiental; Gestão de Bacias Hidrográficas, Qualidade de Água

Endereço: Rua Capitão Rebelinho 679, apt 901 Pina CEP 51011-010 Recife (PE)

E-mail: mariadocarmo.sobral@gmail.com 